\title{
TOPSIS and Modified TOPSIS: A Comparative Analysis
}

\author{
Subrata Chakraborty \\ Centre for Advanced Modelling and Geospatial Information Systems \\ (CAMGIS), School of Information, Systems \& Modelling, Faculty of \\ Engineering \& IT, University of Technology Sydney, NSW, Australia \\ Subrata.Chakraborty@uts.edu.au
}

\begin{abstract}
:
Selection of an appropriate Multiple Attribute Decision Making (MADM) method for providing a solution to a given MADM problem is always challenging endeavour. The challenge is even greater for situations where for a specific MADM problem there exist multiple MADM methods with similar degree of suitability. The Technique for Order Preference by Similarity to Ideal Solution (TOPSIS) and its dominant variant the Modified TOPSIS methods are two very similar methods applicable to the same type of MADM problems. This study provides extensive simulation-based comparisons and mathematical analysis of these two popular methods in order to clarify the confusion regarding their selection for solving MADM problems.
\end{abstract}

Keywords: TOPSIS, Modified TOPSIS, Euclidean distance, Simulation comparison, MADM, Method selection.

\section{Introduction:}

Selecting appropriate MADM methods is always a challenging task [1]. The need for comparative comparison for methods during selection has been highlighted in studies[2-4]. Within the Multiple Attribute Decision Making (MADM) domain, the Technique for Order Preference by Similarity to Ideal Solution (TOPSIS) $[5,6]$ is highly regarded, applied and adopted MADM method. A variant of TOPSIS named modified TOPSIS was developed with the argument about how the attribute weight should be applied while solving MADM problems [7]. Both TOPSIS and modified TOPSIS have been applied for problem solving by various researchers.

TOPSIS has been used extensively with over 13000 citations [8] for practical MADM problem due to its sound mathematical foundation, simplicity, ease of applicability [9]. TOPSIS has inspired scores of new methods and comparative analysis based on it $[10,11]$. TOPSIS has been widely used in areas such as purchase decisions and outsource provider selection $[12,13]$, manufacturing decision making [14, 15], financial performance analysis [16], service quality assessment [17], educational selection applications [18], strategy evaluation [19], and critical mission planning [20].

With close to 1000 citations [21] Modified TOPSIS has been used for comparative studies in attribute weight estimations [22]. The study is also applied in resource management [23], software selection [24], environmental assessment [25], sustainability assessment [26], material selection [27], other method development [28-30]. 
TOPSIS $[5,6]$ is one of the fundamental methods in MADM domain and has been immensely popular in applications and as foundation to numerous method development. The modified TOPSIS [7] which is also built upon the TOPSIS method, gained application popularity due to its novel use of the objective weight elicitation process based on Shannon's [31] entropy theory. Both these methods use the same Euclidean distance measure except for when the attribute weight is to be incorporated with the solution. It is very challenging for the decision makers to choose between these two methods due to their extreme similarity between them in their mathematical structures and their applicability to solve the same kind of MADM problems such as water management application [23, 32], airline assessment [33, 34], supplier selection [35]. Thus, there is a need to evaluate and compare these two methods to justify their suitability and applications.

In following sections, we first present the TOPSIS and the Modified TOPSIS methods. Case study-based comparisons are then presented followed by mathematical analysis.

\section{Background of TOPSIS and Modified TOPSIS}

We first present the generic form of the MADM problem before the TOPSIS and the Modified TOPSIS methods are explained by considering how these methods are applied to solve a given MADM problem.

\subsection{MADM Problem Formulation}

The generic MADM problem has the objective of assessing and ranking alternatives $A_{i}(i=1,2, \ldots, I)$ on the basis of certain attributes $C_{j}(j=1,2, \ldots, J)$. The set of alternatives $A_{i}$ represents the available options for the decision maker which requires to be ranked. The set of attributes $C_{j}$ represents the factors influencing te decision maker's choice while ranking the alternatives $A_{i} . W_{j}(j=1,2, \ldots, J)$ represents the weights indicating the relative significance of the attributes $C_{j}$. Attribute weights can be presented as a vector as shown in Eq.1 $[4,6,36]$.

$$
W=\left\{W_{j}\right\}
$$

The decision maker's preference for every alternative $A_{i}$ against every attribute $C_{j}$ are known as the performance rating $x_{i j}(i=1,2, \ldots, I ; j=1,2, \ldots, J)$. As shown in Eq. 2, the performance ratings for each alternative against each attribute can be displayed in the form of a decision matrix [4-6, 9, 36, 37].

$$
X=\left[\begin{array}{cccc}
x_{11} & x_{12} & \ldots & x_{1 J} \\
x_{21} & x_{22} & \ldots & x_{2 J} \\
\ldots & \ldots & \ldots & \ldots \\
x_{I 1} & x_{I 2} & \ldots & x_{I J}
\end{array}\right]
$$

With the defined decision matrix $X$ and weight vector $W$ in Eq. $1 \& 2$, the MADM problem $\Phi$ is represented in Eq. 3 [4, 36]

$$
\Phi=\{X, W\}
$$

The given MADM problem $\Phi$ can be solved by applying a range of suitable MADM methods. Generally, the MADM methods require (a) a normalisation procedure, and (b) a score aggregation technique. The normalisation transforms the performance rating $x_{i j}$ to a comparable 
measurement unit. An overall weighted score $V_{i}(i=1,2, \ldots, I)$ for each alternative is calculated by applying the aggregation which combines the weights with the performance ratings. The final ranking of the alternatives is done using the overall score $[4-6,36]$.

\subsection{The TOPSIS method}

TOPSIS is based on the fundamental premise that the best solution has the shortest distance from the positive-ideal solution, and the longest distance from the negative-ideal one. Alternatives are ranked with the use of an overall index calculated based on the distances from the ideal solutions. [3-5, 36, 38].

The TOPSIS method can be explained as a set of stages shown below:

Stage 1: Calculate the normalised performance ratings.

Vector Normalisation is applied to obtain normalised performance ratings from Eq. 2.

In this procedure, each performance rating $x_{i j}$ in $X$ is divided by its norm. The normalised ratings $y_{i j}(i=1,2, \ldots, I ; j=1,2, \ldots, J)$ can be calculated by Eq. 4 .

$$
y_{i j}=x_{i j} / \sqrt{\sum_{i=1}^{I} x^{2} i j}
$$

Although this conversion process makes comparison across attributes easier through the use of dimensionless units, it has the challenges in performing straightforward comparison due to non-equal scale length [3, 4, 6, 36, 39].

The normalised performance ratings $y_{i j}$ can be given as a matrix $\mathrm{Y}$ as shown in Eq.5.

$$
Y=\left[\begin{array}{cccc}
y_{11} & y_{12} & \ldots & y_{1 J} \\
y_{21} & y_{22} & \ldots & y_{2 J} \\
\ldots & \ldots & \ldots & \ldots \\
y_{I 1} & y_{I 2} & \ldots & y_{I J}
\end{array}\right]
$$

Stage 2: Integrate weigh with ratings.

The weighted and normalised performance rating $v_{i j}(i=1,2, \ldots, I ; j=1,2, \ldots, J)$ is calculated from Eq. $1 \& 5$ as shown in Eq. 6 . These weighted ratings are combined to form the weighted-normalised decision matrix $V$ in Eq. 7 [3-5, 36].

$$
\begin{aligned}
& v_{i j}=W_{j}^{*} y_{i j} ; i=1,2, \ldots, I ; j=1,2, \ldots, J . . \\
& V=\left[\begin{array}{cccc}
v_{11} & v_{12} & \ldots & v_{1 J} \\
v_{21} & v_{22} & \ldots & v_{2 J} \\
\ldots & \ldots & \ldots & \ldots \\
v_{I 1} & v_{I 2} & \ldots & v_{I J}
\end{array}\right]
\end{aligned}
$$

Stage 3: Find positive and negative ideal solutions. 
$A^{*}$ and $A^{-}$are denoted as the positive and negative ideal solution sets respectively which can be detected from Eq. 7 as

$$
\begin{aligned}
& A^{*}=\left[v_{1}^{*}, v_{2}^{*}, \ldots, v_{J}^{*}\right] \\
& A^{-}=\left[v_{1}^{-}, v_{2}^{-}, \ldots, v_{J}^{-}\right]
\end{aligned}
$$

Where, $v_{j}^{*}=\left\{\begin{array}{c}\max v_{i j}, \text { if } j \text { is a benefit attribute } \\ \min v_{i j}, \text { if } j \text { is a cost attribute }\end{array}\right.$

$$
v_{j}^{-}=\left\{\begin{array}{l}
\min v_{i j}, \text { if } j \text { is a benefitattribute } \\
\max v_{i j}, \text { if } j \text { is a cost attribute }[4,5,36]
\end{array}\right.
$$

Stage 4: Obtain the separation values

The separation measure is the distance of each alternative rating from both the positive and negative ideal solutions which is obtained by applying the Euclidean distance theory. Eq. 10 \& 11 show the process for positive and negative separation calculations respectively $[4-6,9,36]$.

$$
\begin{aligned}
& S_{i}^{*}=\sqrt{\sum_{j=}^{J}\left(v_{i j}-v_{j}^{*}\right)^{2}}, \\
& S_{i}^{-}=\sqrt{\sum_{j=}^{J}\left(v_{i j}-v_{j}^{-}\right)^{2}},
\end{aligned}
$$

Stage 5: Calculate the overall preference score

The overall preference score $V_{i}$ for each alternative $A_{i}$ is obtained as shown in Eq. 12 .

$$
V_{i}=\frac{S_{i}^{-}}{S_{i}^{-}+S_{i}^{*}}
$$

Alternatives are ranked based on higher $V_{i}$ values $[4-6,9,36]$.

\subsection{The Modified TOPSIS method}

Modified TOPSIS incorporates the attribute weights with the performance ratings in a slightly different manner compared to the TOPSIS method. Similar to TOPSIS, the overall performance score is obtained from the distance from positive and negative solutions. The distance is related with the alternative weights. The modified TOPSIS proposes the use of alternative weights with the Euclidean distances [7]. Modified TOPSIS inherits all the positive aspects of TOPSIS and supposedly rectifies the use of non-weighted Euclidean distance in TOPSIS.

The modified TOPSIS method is explained through the following stages.

Stage 1: Normalise the original decision matrix

The normalised decision matrix is calculated like the TOPSIS. The matrix can be presented as in Eq. 5 [7].

Sage 2: Identify the ideal solutions

$B^{*}$ and $B^{-}$are defined as the positive and negative ideal solutions respectively and can be obtained in terms of normalised performance ratings from Eq. 5 as

$$
B^{*}=\left[y_{1}^{*}, y_{2}^{*}, \ldots, y_{J}^{*}\right]
$$




$$
B^{-}=\left[y_{1}^{-}, y_{2}^{-}, \ldots, y_{J}^{-}\right]
$$

Where, $y_{j}^{*}=\left\{\begin{array}{l}\max y_{i j} ; \text { for benefit attribute } \\ \min y_{i j} ; \text { for cost attribute }\end{array}\right.$

$$
y_{j}^{-}=\left\{\begin{array}{l}
\min y_{i j} ; \text { for benefit attribute } \\
\max y_{i j} ; \text { for cost attribute }
\end{array}\right.
$$

Stage 3: Obtain the weighted Euclidean distance

The weighted Euclidean distances from the positive and negative ideal solutions for each alternative $A_{i}$ are obtained from Eq. 1, 5, 13, and 14 as

$$
\begin{aligned}
& D_{i}^{*}=\sqrt{\sum_{j=1}^{J} W_{j}\left(y_{i j}-y_{j}^{*}\right)^{2}}, \\
& D_{i}^{-}=\sqrt{\sum_{j=1}^{J} W_{j}\left(y_{i j}-y_{j}^{-}\right)^{2}}
\end{aligned}
$$

Where, $W_{j}(j=1,2, \ldots, J)$ is weights for attributes $C_{j}(j=1,2, \ldots, J)$. [7]

Stage 4. Obtain the overall performance score

The overall score for each alternative $A_{i}$ is obtained as

$$
V_{i}=\frac{D_{i}^{-}}{\left(D_{i}^{*}+D_{i}^{-}\right)}
$$

Performance score $V_{i}$ is utilised to rank the competing alternatives. A higher score value indicates a better alternative performance [7].

\section{Comparisons between TOPSIS and Modified TOPSIS}

The TOPSIS and modified TOPSIS methods are compared under two different weight settings:

(a) all the attributes having equal weights, and (b) the attribute weights are not equal.

\subsection{A practical case study comparison}

Times Higher Education (THE) ranking for universities is one of the most respected ranking for universities worldwide. The ranking of universities (alternatives in this study) is comprised of five key indicators (attributes in this study): i) Teaching, ii) Research, iii) Citations, iv) Industry Income, and v) International Outlook. The five attributes are given weights of 30\%, $30 \%, 30 \%, 2.5 \%$, and $7.5 \%$ respectively with some attributes having weighted sub attributes. Scores in each attribute is collected and adjusted using Z-scoring thus all scores are on the same scale out of 100 and no further normalisation is necessary before obtaining the overall scores [40]. Table 1 shows the scores in each attribute for top 20 universities in the rank. The overall score for each alternative (university) shown in Table 1, is obtained by using the Simple Additive Weighting (SAW) [41] where individual scores in each attribute are multiplied by the relevant weight and then added. This overall score is then used to obtain the ranking. 
Table 1. Top 20 world university ranking scores from Times Higher Education in 2020 [40]

\begin{tabular}{|c|c|c|c|c|c|c|c|}
\hline Rank & Name & $\begin{array}{l}\text { Over } \\
\text { all }\end{array}$ & $\begin{array}{l}\text { Teach } \\
\text { ing }\end{array}$ & $\begin{array}{l}\text { Resear } \\
\text { ch }\end{array}$ & $\begin{array}{l}\text { Citati } \\
\text { ons }\end{array}$ & $\begin{array}{l}\text { Industry } \\
\text { Income }\end{array}$ & $\begin{array}{l}\text { Internat } \\
\text { ional } \\
\text { Outlook }\end{array}$ \\
\hline 1 & University of Oxford & 95.4 & 90.5 & 99.6 & 98.4 & 65.5 & 96.4 \\
\hline 2 & $\begin{array}{l}\text { California Institute of } \\
\text { Technology }\end{array}$ & 94.5 & 92.1 & 97.2 & 97.9 & 88 & 82.5 \\
\hline 3 & $\begin{array}{l}\text { University of } \\
\text { Cambridge }\end{array}$ & 94.4 & 91.4 & 98.7 & 95.8 & 59.3 & 95 \\
\hline 4 & Stanford University & 94.3 & 92.8 & 96.4 & 99.9 & 66.2 & 79.5 \\
\hline 5 & $\begin{array}{l}\text { Massachusetts Institute } \\
\text { of Technology }\end{array}$ & 93.6 & 90.5 & 92.4 & 99.5 & 86.9 & 89 \\
\hline 6 & Princeton University & 93.2 & 90.3 & 96.3 & 98.8 & 58.6 & 81.1 \\
\hline 7 & Harvard University & 93 & 89.2 & 98.6 & 99.1 & 47.3 & 76.3 \\
\hline 8 & Yale University & 91.7 & 92 & 94.8 & 97.3 & 52.4 & 68.7 \\
\hline 9 & University of Chicago & 90.2 & 89.1 & 91.4 & 96.7 & 52.7 & 76 \\
\hline 10 & $\begin{array}{l}\text { Imperial College } \\
\text { London }\end{array}$ & 89.8 & 84.5 & 87.6 & 97 & 69.9 & 97.1 \\
\hline 11 & $\begin{array}{l}\text { University of } \\
\text { Pennsylvania }\end{array}$ & 89.6 & 87.5 & 90.4 & 98.2 & 74 & 65 \\
\hline 12 & $\begin{array}{l}\text { Johns Hopkins } \\
\text { University }\end{array}$ & 89.2 & 81.7 & 91.4 & 98.3 & 91.3 & 73.2 \\
\hline 13 & $\begin{array}{l}\text { University of } \\
\text { California, Berkeley }\end{array}$ & 88.3 & 83 & 90.6 & 99.2 & 46.1 & 70.4 \\
\hline 13 & ETH Zurich & 88.3 & 81.8 & 92.8 & 90.3 & 56.8 & 98.2 \\
\hline 15 & $\mathrm{UCL}$ & 87.1 & 77.8 & 88.7 & 96.1 & 42.7 & 96.2 \\
\hline 16 & Columbia University & 87 & 85.6 & 82.6 & 98.2 & 44.8 & 79.3 \\
\hline 17 & $\begin{array}{l}\text { University of } \\
\text { California, Los } \\
\text { Angeles }\end{array}$ & 86.8 & 83.1 & 88.6 & 97.3 & 51.3 & 64.1 \\
\hline 18 & University of Toronto & 85.5 & 76.6 & 89.5 & 93.6 & 50.5 & 84.7 \\
\hline 19 & Cornell University & 85.1 & 79.7 & 86 & 96.6 & 37.1 & 73.4 \\
\hline 20 & Duke University & 84 & 82.4 & 76.8 & 97 & 99.9 & 61.5 \\
\hline
\end{tabular}

We have utilised these performance scores for the alternatives (universities) against the five attributes as shown in Table 1 and the attribute weights set by THE to obtain rankings. Both TOPSIS and modified TOPSIS methods were used to rank the alternatives (universities). Table 2 shows the ranking outcomes for TOPSIS and Modified TOPSIS compared with the original THE ranking. The ranking outcomes shows that different methods produce different rankings. The TOPSIS rankings were mostly similar for top 10 universities and some rank reversals for other universities. The Modified TOPSIS shows much more variations in the rank. Past studies showed that different ranking outcomes are commonly evident with different methods and have 
suggested techniques to choose the most suitable methods $[2-4,36]$. We do not see any justification from THE ranking documents why SAW was used over other valid and equally suitable methods such as TOPSIS. However, in this study we are concerned about the fact that TOPSIS and Modified TOPSIS produced two ranking outcomes as shown in Table 2, which are vastly different despite their same mathematical origin and strikingly similar structures. This simple case study results highlights the need for through investigation and comparison between TOPSIS and Modified TOPSIS.

Table 2. Top 20 world university ranking comparisons

\begin{tabular}{|l|r|r|r|}
\hline Name & $\begin{array}{l}\text { THE } \\
\text { Rank }\end{array}$ & $\begin{array}{l}\text { TOPSIS } \\
\text { Rank }\end{array}$ & $\begin{array}{l}\text { Modified } \\
\text { TOPSIS } \\
\text { Rank }\end{array}$ \\
\hline University of Oxford & 1 & 1 & 2 \\
\hline California Institute of Technology & 2 & 2 & 1 \\
\hline University of Cambridge & 3 & 3 & 4 \\
\hline Stanford University & 4 & 4 & 5 \\
\hline Massachusetts Institute of Technology & 5 & 7 & 3 \\
\hline Princeton University & 6 & 5 & 6 \\
\hline Harvard University & 7 & 6 & 8 \\
\hline Yale University & 9 & 8 & 11 \\
\hline University of Chicago & 10 & 12 & 12 \\
\hline Imperial College London & 11 & 10 & 7 \\
\hline University of Pennsylvania & 12 & 11 & 13 \\
\hline Johns Hopkins University & 13 & 14 & 15 \\
\hline University of California, Berkeley & 15 & 13 & 10 \\
\hline ETH Zurich & 16 & 16 & 14 \\
\hline UCL & 17 & 15 & 18 \\
\hline Columbia University & 18 & 18 & 19 \\
\hline University of California, Los Angeles & 19 & 19 & 20 \\
\hline University of Toronto & & 20 & 17 \\
\hline Cornell University & & \\
\hline Duke University & & 16 & 9 \\
\hline
\end{tabular}

\subsection{Comparison with equal weight settings}

\subsubsection{Simulation Results}

We conducted a problem-solving simulation with more than 1,000 MADM problems (randomly generated) with equal attribute weight settings. For each problem, the TOPSIS and the modified TOPSIS methods produces the same ranking outcome. This result can be justified by the following mathematical proof.

\subsubsection{Mathematical Analysis}

The TOPSIS Eq. 12 is expanded using Eq. 10 \& 11 as 


$$
V_{i}=\frac{\sqrt{\sum_{j=1}^{J}\left(v_{i j}-v_{j}^{-}\right)^{2}}}{\left(\sqrt{\sum_{j=1}^{J}\left(v_{i j}-v_{j}^{*}\right)^{2}}+\sqrt{\sum_{j=1}^{J}\left(v_{i j}-v_{j}^{-}\right)^{2}}\right)}
$$

Eq. 18 can be further extended by applying Eq. $6 \& 9$ as

$$
V_{i}=\frac{\sqrt{\sum_{j=1}^{J}\left(W_{j} y_{i j}-W_{j} y_{j}^{-}\right)^{2}}}{\left(\sqrt{\sum_{j=1}^{J}\left(W_{j} y_{i j}-W_{j} y_{j}^{*}\right)^{2}}+\sqrt{\sum_{j=1}^{J}\left(W_{j} y_{i j}-W_{j} y_{j}^{-}\right)^{2}}\right)}
$$

Or,

$$
V_{i}=\frac{\sqrt{\sum_{j=1}^{J} W_{j}^{2}\left(y_{i j}-y_{j}^{-}\right)^{2}}}{\left(\sqrt{\sum_{j=1}^{J} W_{j}^{2}\left(y_{i j}-y_{j}^{*}\right)^{2}}+\sqrt{\sum_{j=1}^{J} W_{j}^{2}\left(y_{i j}-y_{j}^{-}\right)^{2}}\right)}
$$

With the equal weight settings, applying $W_{j}=W$ to Eq. 20

$$
V_{i}=\frac{\sqrt{\sum_{j=1}^{J} W^{2}\left(y_{i j}-y_{j}^{-}\right)^{2}}}{\left(\sqrt{\sum_{j=1}^{J} W^{2}\left(y_{i j}-y_{j}^{*}\right)^{2}}+\sqrt{\sum_{j=1}^{J} W^{2}\left(y_{i j}-y_{j}^{-}\right)^{2}}\right)}
$$

or

$$
V_{i}=\frac{\sqrt{\sum_{j=1}^{J}\left(y_{i j}-y_{j}^{-}\right)^{2}}}{\left(\sqrt{\sum_{j=1}^{J}\left(y_{i j}-y_{j}^{*}\right)^{2}}+\sqrt{\sum_{j=1}^{J}\left(y_{i j}-y_{j}^{-}\right)^{2}}\right)}
$$

Similarly, the Modified TOPSIS Eq. 17 can be expanded by using Eq. $15 \& 16$ as

$$
V_{i}=\frac{\sqrt{\sum_{j=1}^{J} W_{j}\left(y_{i j}-y_{j}^{-}\right)^{2}}}{\left(\sqrt{\sum_{j=1}^{J} W_{j}\left(y_{i j}-y_{j}^{*}\right)^{2}}+\sqrt{\sum_{j=1}^{J} W_{j}\left(y_{i j}-y_{j}^{-}\right)^{2}}\right)},
$$

With the equal weight settings, applying $W_{j}=W$ to Eq. 23 


$$
V_{i}=\frac{\sqrt{\sum_{j=1}^{J} W\left(y_{i j}-y_{j}^{-}\right)^{2}}}{\left(\sqrt{\sum_{j=1}^{J} W\left(y_{i j}-y_{j}^{*}\right)^{2}}+\sqrt{\sum_{j=1}^{J} W\left(y_{i j}-y_{j}^{-}\right)^{2}}\right)} ;
$$

or

$$
V_{i}=\frac{\sqrt{\sum_{j=1}^{J}\left(y_{i j}-y_{j}^{-}\right)^{2}}}{\left(\sqrt{\sum_{j=1}^{J}\left(y_{i j}-y_{j}^{*}\right)^{2}}+\sqrt{\sum_{j=1}^{J}\left(y_{i j}-y_{j}^{-}\right)^{2}}\right)}
$$

Comparing Eq. 22 and 25, it is observed that the two methods are the same. This mathematical explanation justifies the same ranking results obtained during the simulation study. It also highlights the extreme structural similarities between the two methods and justifies the need for further investigation under non-equal weights.

\subsection{Comparison with non-equal weight settings}

A simulation study and results are presented before providing a mathematical comparison of the TOPSIS and modified TOPSIS methods under non-equal weight settings.

\subsubsection{Simulation Results}

In this simulation study, the decision matrix from the graduate fellowship applicants ranking case presented by [6] is used. Table 3 shows the decision matrix.

\begin{tabular}{|c|c|c|c|c|c|}
\hline \multirow[b]{2}{*}{ Alternatives } & \multicolumn{5}{|c|}{ Attributes } \\
\hline & $C 1$ & $C 2$ & $C 3$ & C4 & C5 \\
\hline$A 1$ & 690 & 3.1 & 9 & 7 & 4 \\
\hline$A 2$ & 590 & 3.9 & 7 & 6 & 10 \\
\hline$A 3$ & 600 & 3.6 & 8 & 8 & 7 \\
\hline$A 4$ & 620 & 3.8 & 7 & 10 & 6 \\
\hline$A 5$ & 700 & 2.8 & 10 & 4 & 6 \\
\hline$A 6$ & 650 & 4 & 6 & 9 & 8 \\
\hline
\end{tabular}

Table 3. Graduate fellowship decision matrix for the simulation [6]

The simulation is started with equal attribute weight $W=(0.2,0.2,0.2,0.2,0.2)$ for the five attributes. With this equal weight setting, the decision problem is solved with both the TOPSIS and modified-TOPSIS. The ranking outcomes obtained, are the same and are used as the base outcomes.

The attribute weights are then changed gradually with a step of 0.1 producing 126 distinct weight sets between the range of $(0.6,0.1,0.1,0.1,0.1)$ and $(0.1,0.1,0.1,0.1,0.6)$. The incremental step is decided to be 0.1 because it produces significant result variations required for this study. 
For each set of weights, the MADM problem is then solved using both the TOPSIS and the modified TOPSIS methods. The simulation shows that $70 \%$ of the 126 weight sets generates distinct ranking outcomes for the two methods.

The simulation results and the previous sections for equal weight settings highlight the fact that the only difference between TOPSIS and modified TOPSIS is in how the attribute weight is incorporated during calculations. A closer inspection of expanded TOPSIS Equation (20) and expanded modified TOPSIS Equation (23) shows that the only difference between the two methods is that in TOPSIS, $W_{j}^{2}$ is used but in modified TOPSIS $W_{j}$ is used while calculating the distances from the positive and the negative ideal solutions. Thus, further mathematical analysis under non-equal weight settings is required to establish the differences of these methods.

\subsubsection{Mathematical Analysis}

The modified TOPSIS method suggests that the distance between performance ratings should be weighted, rather than the performance ratings as done in TOPSIS. Considering this argument rational and valid, the equation is derived from the basic Euclidean distance theory [42].

A single dimension problem with two vectors $\mathrm{P}\left[x_{1}\right]$ and $\mathrm{Q}\left[x_{2}\right]$ shown in Fig.1.

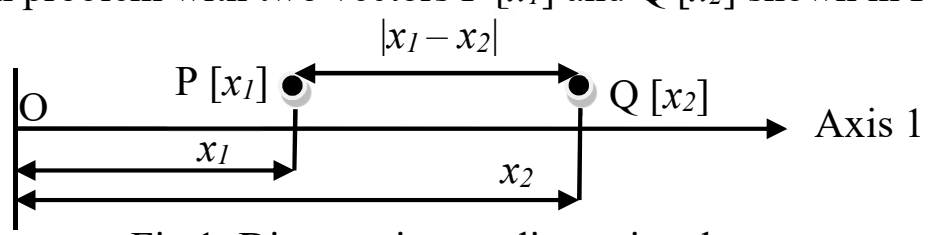

Fig 1. Distance in one dimensional space

The distance between $\mathrm{P}$ and $\mathrm{Q}$ is obtained as

$$
|\mathrm{PQ}|=d_{x}=\left|x_{1}-x_{2}\right|
$$

If the dimension has any weight associated with it, then the weighted distance can be expressed as

$$
D_{x}=W_{1}\left|x_{1}-x_{2}\right|
$$

Now consider the problem with two dimensions with vectors $\mathrm{P}\left[x_{1}, x_{2}\right]$ and $\mathrm{Q}\left[y_{1}, y_{2}\right]$ as shown in Fig. 2.

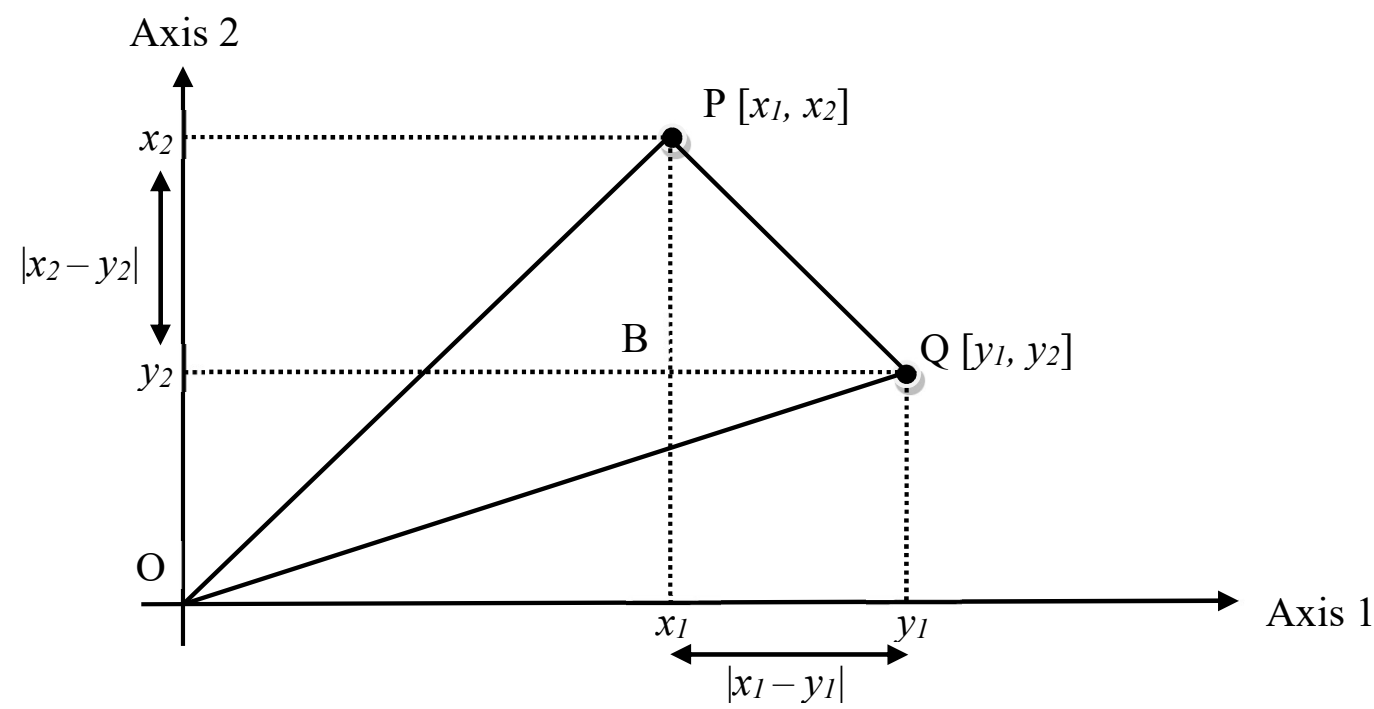


Fig. 2. Distance in two-dimensional space (Source: Adapted from Greenacre [42])

Using the Pythagoras' theorem for right-angled triangle, from Figure 2 we can write the distance between $\mathrm{P}$ and $\mathrm{Q}$ as

$$
|\mathrm{PQ}|^{2}=\left(d_{x y}\right)^{2}=\left(x_{1}-y_{1}\right)^{2}+\left(x_{2}-y_{2}\right)^{2}
$$

or

$$
d_{x y}=\sqrt{\left(x_{1}-y_{1}\right)^{2}+\left(x_{2}-y_{2}\right)^{2}}
$$

By applying Equations (26) and (27) the two-dimensional weighted Euclidean distance can be obtained from Equation (29) as

$$
D_{x y}=\sqrt{\left(W_{1}\left|x_{1}-y_{1}\right|\right)^{2}+\left(W_{2}\left|x_{2}-y_{2}\right|\right)^{2}}
$$

Similarly, the Euclidean distance and the weighted Euclidean distance can be obtained for three dimensional problems with $\mathrm{P}\left[x_{1}, x_{2}, x_{3}\right]$ and $\mathrm{Q}\left[y_{1}, y_{2}, y_{3}\right]$ as shown in Equations (31) and (32) respectively.

$$
\begin{aligned}
& d_{x y}=\sqrt{\left(x_{1}-y_{1}\right)^{2}+\left(x_{2}-y_{2}\right)^{2}+\left(x_{3}-y_{3}\right)^{2}} \\
& D_{x y}=\sqrt{\left(W_{1}\left|x_{1}-y_{1}\right|\right)^{2}+\left(W_{2}\left|x_{2}-y_{2}\right|\right)^{2}+\left(W_{3}\left|x_{3}-y_{3}\right|\right)^{2}}
\end{aligned}
$$

The weighted Euclidean distance for vectors $\mathrm{P}$ and $\mathrm{Q}$ with $j(j=1,2, \ldots, J)$ dimensions can be obtained similarly as

$$
D_{x y}=\sqrt{\sum_{j=1}^{J}\left(W_{j}\left|x_{j}-y_{j}\right|\right)^{2}}
$$

or

$$
D_{x y}=\sqrt{\sum_{j=1}^{J} W_{j}^{2}\left(x_{j}-y_{j}\right)^{2}}
$$

The mathematical derivation of Equation (34) proves that while calculating the weighted Euclidean distance, squared weight should be used. The multi-dimension used in the derivation is analogous to MADM problem solving by TOPSIS and modified TOPSIS where the attributes are considered as dimensions. Comparisons between Equation (34) and the TOPSIS Equation (20) and the modified TOPSIS Equation (23) prove that the TOPSIS method applies the weight in a correct manner.

The concept of distance weighting introduced in the modified TOPSIS is valid and rational. The modified TOPSIS method derives objective weight using the entropy concept $[31,43]$ based on information variation in the MADM problem [7]. This objective weight shows the relative importance of the attributes in terms of their impacts on the decision outcomes. The objective weight should be treated differently from the attribute weights provided by the decision maker and should never be used in the process of solving the MADM problem. The objective weight certainly can indicate the decision maker regarding the significance of attributes so that the decision maker can be careful while solving the problem. 
On the other hand, although the TOPSIS method uses the weighting of normalised performance rating and does not explicitly applies the distance weighting concept, the mathematical structure of TOPSIS is implicitly the same as that of the weighted Euclidean distance.

\section{Conclusions}

This study has provided extensive simulation and mathematical proof-based comparisons between two widely used MADM methods: the TOPSIS method and the modified TOPSIS method. The evaluations have shown the validity of the arguments presented for the modified TOPSIS however the application of the weight incorporation process during the aggregation is inappropriate. The objective weight elicitation concept in modified TOPSIS is valid and highly useful to understand criteria significance. However, the way weight is incorporated will produce incorrect ranking, as the weigh is squared in the aggregation process. It has been proved that the TOPSIS method provides correct weight aggregation process, and it should be used for MADM problems where both TOPSIS and modified TOPSIS could be applied. This study will benefit the decision makers who are not sure about choosing between these two methods and would eliminate the confusions among practitioners.

\section{References}

1. Yeh, C.H., A problem-based selection of multi-attribute decision-making methods. International Transactions in Operational Research, 2002. 9(2): p. 169-181.

2. Chakraborty, S. and C.-H. Yeh. A simulation based comparative study of normalization procedures in multiattribute decision making. in Proceedings of the 6th Conference on 6th WSEAS Int. Conf. on Artificial Intelligence, Knowledge Engineering and Data Bases. 2007.

3. Chakraborty, S. and C.-H. Yeh. A simulation comparison of normalization procedures for TOPSIS. in 2009 International Conference on Computers \& Industrial Engineering. 2009. IEEE.

4. Chakraborty, S. and C.-H. Yeh. Comparison based group ranking outcome for multiattribute group decisions. in 2012 UKSim 14th International Conference on Computer Modelling and Simulation. 2012. IEEE.

5. Hwang, C.L. and K. Yoon, Multiple Attribute Decision Making Methods and Applications. 1981, Berlin Heidelberg: Springer.

6. Yoon, K.P. and C.-L. Hwang, Multiple attribute decision making: an introduction. Vol. 104. 1995: Sage publications.

7. Deng, H., C.-H. Yeh, and R. Willis, Inter-company comparison using modified TOPSIS with objective weights. Computers Operations Research, 2000. 27(10): p. 963-973.

8. scholar, G. Google scholar - TOPSIS. 2020 [cited 2020 12/04/2020]; Available from: https://scholar.google.com/scholar?hl=en\&as_sdt=0\%2C5\&q=Multiple+Attribute+De cision+Making+Methods+and + Applications\&btnG $=$.

9. Yeh, C.H., The selection of multiattribute decision making methods for scholarship student selection. International Journal of Selection Assessment, 2003. 11(4): p. 289296.

10. Zavadskas, E.K., et al., Development of TOPSIS method to solve complicated decisionmaking problems-An overview on developments from 2000 to 2015. International Journal of Information Technology \& Decision Making, 2016. 15(03): p. 645-682. 
11. Kuo, T., A modified TOPSIS with a different ranking index. European Journal of Operational Research, 2017. 260(1): p. 152-160.

12. Kahraman, C., et al., Information systems outsourcing decisions using a group decision-making approach. Engineering Applications of Artificial Intelligence, 2009. 22(6): p. 832-841.

13. Shyur, H.-J. and H.-S. Shih, A hybrid MCDM model for strategic vendor selection. Mathematical computer modelling, 2006. 44(7-8): p. 749-761.

14. Agrawal, V., V. Kohli, and S. Gupta, Computer aided robot selection: the 'multiple attribute decision making'approach. The International Journal of Production Research, 1991. 29(8): p. 1629-1644.

15. Parkan, C. and M.-L. Wu, Decision-making and performance measurement models with applications to robot selection. Computers Industrial Engineering

1999. 36(3): p. 503-523.

16. Feng, C.-M. and R.-T. Wang, Considering the financial ratios on the performance evaluation of highway bus industry. Transport reviews, 2001. 21(4): p. 449-467.

17. Laroche, M., A. Mukherjee, and P. Nath, An empirical assessment of comparative approaches to service quality measurement. Journal of services marketing, 2005.

18. Nanayakkara, C., et al., Deciding discipline, course and university through TOPSIS. Studies in Higher Education, 2019: p. 1-16.

19. Ture, H., S. Dogan, and D. Kocak, Assessing Euro 2020 strategy using multi-criteria decision making methods: VIKOR and TOPSIS. Social Indicators Research, 2019. 142(2): p. 645-665.

20. Tavana, M. and A. Hatami-Marbini, A group AHP-TOPSIS framework for human spaceflight mission planning at NASA. Expert Systems with Applications

2011. 38(11): p. 13588-13603.

21. scholar, G. Google scholar -Modified TOPSIS. 2020 [cited 2020 12/04/2020]; Available from: https://scholar.google.com/scholar?hl=en\&as sdt=0\%2C5\&q=Intercompany + comparison + using + modified + TOPSIS + with + objective + weights $\& b \operatorname{btn}=$.

22. García, F., F. Guijarro, and I. Moya, A goal programming approach to estimating performance weights for ranking firms. Computers Operations Research, 2010. 37(9): p. 1597-1609.

23. Meshram, S.G., et al., Application of SAW and TOPSIS in Prioritizing Watersheds. Water Resources Management, 2020: p. 1-18.

24. Byun, H. and K. Lee, A decision support system for the selection of a rapid prototyping process using the modified TOPSIS method. The International Journal of Advanced Manufacturing Technology, 2005. 26(11-12): p. 1338-1347.

25. Zhou, P., B. Ang, and K. Poh, Comparing aggregating methods for constructing the composite environmental index: An objective measure. Ecological Economics, 2006. 59(3): p. 305-311.

26. Zhang, L., et al., City sustainability evaluation using multi-criteria decision making with objective weights of interdependent criteria. Journal of Cleaner Production, 2016. 131: p. 491-499.

27. Jahan, A., et al., A framework for weighting of criteria in ranking stage of material selection process. The International Journal of Advanced Manufacturing Technology, 2012. 58(1-4): p. 411-420.

28. Zhou, M., et al., Evidential reasoning approach with multiple kinds of attributes and entropy-based weight assignment. Knowledge-Based Systems, 2019. 163: p. 358-375.

29. Dahooie, J.H., et al., An improved fuzzy MULTIMOORA approach for multi-criteria decision making based on objective weighting method (CCSD) and its application to 
technological forecasting method selection. Engineering Applications of Artificial Intelligence, 2019. 79: p. 114-128.

30. Llamazares, B., Using interval weights in MADM problems. Computers \& Industrial Engineering, 2019. 136: p. 345-354.

31. Shannon, C.E., A mathematical theory of communication. Bell system technical journal, 1948. 27(3): p. 379-423.

32. Arabameri, A., et al., GIS-based groundwater potential mapping in Shahroud plain, Iran. A comparison among statistical (bivariate and multivariate), data mining and MCDM approaches. Science of the total environment, 2019. 658: p. 160-177.

33. Chang, Y.-H. and C.-H. Yeh, Evaluating airline competitiveness using multiattribute decision making. Omega, 2001. 29(5): p. 405-415.

34. Aydogan, E.K., Performance measurement model for Turkish aviation firms using the rough-AHP and TOPSIS methods under fuzzy environment. Expert Systems with Applications, 2011.38(4): p. 3992-3998.

35. Lin, C.-T., C.-B. Chen, and Y.-C. Ting, An ERP model for supplier selection in electronics industry. Expert Systems with Applications, 2011. 38(3): p. 1760-1765.

36. Chakraborty, S. and A. Mandal. A Novel TOPSIS based Consensus Technique for Multiattribute Group Decision Making. in 2018 18th International Symposium on Communications and Information Technologies (ISCIT). 2018. IEEE.

37. Belton, V. and T. Stewart, Multiple criteria decision analysis: an integrated approach. 2002: Springer Science \& Business Media.

38. Zeleny, M., Multiple attributes decision maki. 1982, New York: McGraw-Hill.

39. Olson, D.L., Comparison of three multicriteria methods to predict known outcomes. European Journal of operational research, 2001. 130(3): p. 576-587.

40. Education, T.H. World University Rankings 2020: methodology. 2020 [cited 2020 5/2/2020]; Available from: https:/www.timeshighereducation.com/world-universityrankings/world-university-rankings-2020-methodology.

41. Zionts, S. and J. Wallenius, An interactive multiple objective linear programming method for a class of underlying nonlinear utility functions. Management Science, 1983. 29(5): p. 519-529.

42. Greenacre, M. Chapter 4: Measures of Distance Between Samples: Euclidean. 2008 [cited $2020 \quad 05 / 02 / 2020] ;$ Available from: http://www.econ.upf.edu/ michael/stanford/maeb4.pdf.

43. Shannon, C.E. and W. Weaver, The mathematical theory of communication. 1998: University of Illinois press. 